\title{
Simulations of chlorophyll fluorescence incorporated into the Community Land Model version 4
}

Lee, Jung-Eun ; Berry, Joseph A ; van der Tol, Christiaan ; Yang, Xi ; Guanter, Luis ; Damm, Alexander ; Baker, Ian ; Frankenberg, Christian

\begin{abstract}
Several studies have shown that satellite retrievals of solar-induced chlorophyll fluorescence (SIF) provide useful information on terrestrial photosynthesis or gross primary production (GPP). Here, we have incorporated equations coupling SIF to photosynthesis in a land surface model, the National Center for Atmospheric Research Community Land Model version 4 (NCAR CLM4) and have demonstrated its use as a diagnostic tool for evaluating the calculation of photosynthesis, a key process in a land surface model that strongly influences the carbon, water, and energy cycles. By comparing forward simulations of SIF, essentially as a byproduct of photosynthesis, in CLM4 with observations of actual SIF, it is possible to check whether the model is accurately representing photosynthesis and the processes coupled to it. We provide some background on how SIF is coupled to photosynthesis, describe how SIF was incorporated into CLM4, and demonstrate that our simulated relationship between SIF and GPP values are reasonable when compared with satellite (Greenhouse gases Observing SATellite; GOSAT) and in situ flux-tower measurements. CLM4 overestimates SIF in tropical forests, and we show that this error can be corrected by adjusting the maximum carboxylation rate (Vmax) specified for tropical forests in CLM4. Our study confirms that SIF has the potential to improve photosynthesis simulation and thereby can play a critical role in improving land surface and carbon cycle models.
\end{abstract}

DOI: https://doi.org/10.1111/gcb.12948

Posted at the Zurich Open Repository and Archive, University of Zurich

ZORA URL: https://doi.org/10.5167/uzh-111004

Journal Article

Accepted Version

Originally published at:

Lee, Jung-Eun; Berry, Joseph A; van der Tol, Christiaan; Yang, Xi; Guanter, Luis; Damm, Alexander; Baker, Ian; Frankenberg, Christian (2015). Simulations of chlorophyll fluorescence incorporated into the Community Land Model version 4. Global Change Biology, 21(9):3469-3477.

DOI: https://doi.org/10.1111/gcb.12948 


\title{
Received date : 21-Feb-2015
}

\author{
Revised date :21-Feb-2015
}

Accepted date :02-Mar-2015

\section{Article Type: Primary Research Articles}

\section{Simulations of chlorophyll fluorescence incorporated into the Community Land Model version 4}

\author{
Jung-Eun Lee ${ }^{1 *}$, Joseph A. Berry ${ }^{2}$, Christiaan van der Tol $^{3}$, Xi Yang ${ }^{1}$, Luis Guanter ${ }^{4}$, Alexander \\ Damm $^{5}$, Ian Baker ${ }^{6}$, Christian Frankenberg ${ }^{7}$
}

1. Department of Geological Sciences, Brown University, Providence RI, USA

2. Department of Global Ecology, Carnegie Institution of Washington, Stanford, CA, USA

3. Geo-Information Science and Earth Observation, The University of Twente, The Netherlands

4. Institute for Space Sciences, Free University of Berlin, Germany

5. Department of Geography, University of Zurich, Zurich, Switzerland

6. Department of Atmospheric Science, Colorado State University, Fort Collins, CO, USA

7. Jet Propulsion Laboratory, California Institute of Technology, Pasadena, CA, USA

*: Corresponding author: leeje@brown.edu, Telephone: 1-401-863-6465, Fax: 1-401-863-2058

This article has been accepted for publication and undergone full peer review but has not been through the copyediting, typesetting, pagination and proofreading process, which may lead to differences between this version and the Version of Record. Please cite this article as doi: $10.1111 / \mathrm{gcb} .12948$

This article is protected by copyright. All rights reserved. 


\begin{abstract}
Several studies have shown that satellite retrievals of solar-induced chlorophyll fluorescence (SIF) provide useful information on terrestrial photosynthesis or gross primary production (GPP). Here, we have incorporated equations coupling SIF to photosynthesis in a land surface model, the National Center for Atmospheric Research Community Land Model version 4 (NCAR CLM4) and have demonstrated its use as a diagnostic tool for evaluating the calculation of photosynthesis, a key process in a land surface model that strongly influences the carbon, water, and energy cycles. By comparing forward simulations of SIF, essentially as a byproduct of photosynthesis, in CLM4 with observations of actual SIF, it is possible to check whether the model is accurately representing photosynthesis and the processes coupled to it. We provide some background on how SIF is coupled to photosynthesis, describe how SIF was incorporated into CLM4, and demonstrate that our simulated relationship between SIF and GPP values are reasonable when compared with satellite (Greenhouse gases Observing SATellite; GOSAT) and in situ flux-tower measurements. CLM4 overestimates SIF in tropical forests, and we show that this error can be corrected by adjusting the maximum carboxylation rate $\left(\mathrm{V}_{\max }\right)$ specified for tropical forests in CLM4. Our study confirms that SIF has the potential to improve photosynthesis simulation and thereby can play a critical role in improving land surface and carbon cycle models.
\end{abstract}

\title{
Introduction
}

Plant photosynthesis is essential for life on Earth. Not only does photosynthesis provide food and oxygen for most living organisms, but it indirectly influences global hydrological cycles by controlling transpiration, the process in which soil water is drawn through the leaves to the 
atmosphere. Land surface models have long included equations for photosynthesis because a large part of latent heat release is accomplished by transpiration while plants photosynthesize [Sellers et al., 1995]. Most advanced land-surface models today calculate terrestrial carbon uptake and transpiration based on the amount of calculated photosynthesis. The water exchange between the land surface and atmosphere during transpiration is an important determinant of precipitation [e.g., Koster et al, 2000, Lee and Boyce, 2010, Lee et al., 2013]. Accurate calculation of photosynthesis is, therefore, crucial for the simulation of energy, water, and carbon balance for the land surface.

Many uncertainties arise when estimating terrestrial carbon uptake and thus make the projection of future $\mathrm{CO}_{2}$ concentration unreliable [Friedlingstein et al., 2006]. For example, the response of tropical forests significantly contributes to the variation in carbon uptake of terrestrial ecosystems [Friedlingstein et al., 2006], but even the observed response of tropical forests during the dry season or drought events has been a source of a debate [e.g. Saleska et al., 2007; Samanta et al., 2010] because traditional greenness indices measure potential, and not actual photosynthesis. As expected from difficulties in observing productivity over tropics, model projections of productivity in tropical forests are also uncertain. One coupled carbon-climate model even predicts that Amazonian forests may collapse as a result of increasing temperature and decreasing precipitation in a world with high $\mathrm{CO}_{2}$ concentrations [Cox et al., 2000]. Increasing atmospheric $\mathrm{CO}_{2}$, however, may partly counteract such predictions, as reported in a recent study suggesting that the degree of forest loss is strongly dependent on forest response to $\mathrm{CO}_{2}$ fertilization, which may slow or even prevent a widespread forest dieback [Huntingford et al., 2013]. Understanding how plant productivity responds to environmental conditions is crucial for predicting the response of carbon uptake by plants and for predicting the ensuing climate change, yet quantifying 
terrestrial productivity is challenging beyond the scale of a single leaf or a plant [Asner and Alencar, 2011]. Thus, a new approach of estimating photosynthesis is necessary.

A portion of the solar energy (1 2\%) captured by chlorophyll is re-emitted as fluorescence. This provides a distinct "glow" from plants at wavelengths between 650 and about $800 \mathrm{~nm}$ with two peak emissions at 685 and $740 \mathrm{~nm}$ that are quite specific for the presence of green plants [Lichtenthaler and Rinderle, 1988]. When plants experience stress and non-photochemical quenching (NPQ) increases, both photosynthesis and fluorescence generally decrease (more details in section 3), and thus, fluorescence can be used as a probe to the photosynthesis process. Leaf-scale studies show that physiological effects of drought lead to a decrease of the light-useefficiency (LUE) for photosynthesis and are associated with a decrease in fluorescence yield [Flexas et al., 2002, Amoros-Lopez et al., 2008]. Measurements of sun-induced fluorescence (SIF) of a sorghum canopy that experienced an episode of drought demonstrate that fluorescence declines with water stress whereas NDVI (and presumably light interception) remains constant [Daumard et al., 2010]. Satellite measurements of SIF from the Japan Aerospace Exploration Agency Greenhouse gases Observing SATellite (JAXA GOSAT) have shown a clear link with plant productivity [e.g., Frankenberg et al., 2011a and b; Joiner et al., 2011]. The intensity of chlorophyll fluorescence measured by GOSAT and the Global Ozone Monitoring Experiment-2 (GOME-2) satellite exhibit a strong linear correlation with estimates of GPP [Frankenberg et al., 2011; Guanter et al, 2014]. Lee et al. (2013) demonstrate that GOSAT SIF measurements over tropical forests show clear water stress signals in the midday that are not well-represented in traditional reflectance-based indices such as NDVI or EVI.

This article is protected by copyright. All rights reserved. 
Here we have incorporated SIF into a land-surface model, the National Center for Atmospheric Research Community Land Model version 4 (NCAR CLM4), to improve our understanding of GPP modeling and to suggest improvements for GPP formulations within the NCAR CLM4. By comparing forward simulations of SIF, essentially as a product of photosynthesis, in CLM4 with observations of actual SIF it is possible to check whether the model is accurately representing photosynthesis and the processes coupled to it. We begin by introducing the models and data that we used, and then we explain how we incorporated SIF using existing theory and data (section 2). In section 3, we focus on the functional relationship between SIF and GPP by using the Soil Canopy Observation of Photochemistry and Energy fluxes (SCOPE) model, which has been used in fluorescence studies [van der Tol et al., 2009b, 2014; Lee et al., 2013] to examine how GPP and SIF respond to changing light intensity and imposed stress levels. In the results section for the NCAR CLM4 (section 4), we compare the CLM results with satellite and in situ observations from flux towers to demonstrate the feasibility of our model for studying SIF (and GPP). We summarize our findings in section 5 .

\section{Material and Methods}

\section{SCOPE model}

We use the SCOPE model to calculate the response of fluorescence to environmental changes and to convert leaf-level fluorescence to satellite-observed fluorescence because SCOPE incorporates explicit radiative transfer in the canopy. SCOPE [Van der Tol, 2009b] is a radiative-transfer model for optical and thermal radiation to which a Soil-Vegetation-Atmosphere-Transfer (SVAT) scheme was added for calculating canopy photosynthesis and energy balance fluxes. Photosynthesis is calculated using Collatz et al. (1991) and Collatz et al. (1992) for C3 and C4 plants, respectively. The radiative transfer component of the model is based on the SAIL

This article is protected by copyright. All rights reserved. 
(Scattering of Arbitrarily Inclined Leaves) model of Verhoef (1984) in which the canopy is divided into layers of leaves characterized by leaf inclination distribution function. SAIL stochastically calculates direct radiation, upward and downward diffuse radiation, and radiation in the direction of the observer. The SAIL concept is applied to three sources of radiation in SCOPE: (1) to direct and diffuse ambient radiation, (2) to thermal radiation emitted by soil and leaves, and (3) to radiation emitted as fluorescence. For each leaf layer and leaf-inclination class, the net (absorbed) radiation is calculated.

Fluorescence emission spectra at leaf level are calculated as a function of leaf properties with the model FLUSPECT [Verhoef, 2007]. The response of leaf fluorescence to weather conditions was originally calculated with Van der Tol et al. (2009a), but this model has been replaced by a simpler equation that has been calibrated to experimental data [van der Tol et al., 2014], explained in section 2.3 .

\section{NCAR CLM4}

We use the NCAR CLM4 to study photosynthesis and fluorescence at an actual grid point at different times of the day or season. CLM 4 [Lawrence et al., 2011] is the land component of the Community Earth System Model (CESM), which has been widely used in climate science studies [e.g. Solomon et al., 2007]. The land component of the model simulates $\mathrm{CO}_{2}$, water, momentum, and energy exchanges between the land surface and atmosphere. $\mathrm{CO}_{2}$ uptake (photosynthesis) and water loss (transpiration) by plants are determined as a diffusive flux between the stomata and the surrounding atmosphere. Soil water moves from the soil to the atmosphere following the prescribed root density in each soil layer. We used the prescribed monthly leaf-area index derived from satellite data. We ran CLM4 using precipitation, wind, temperature, specific humidity and 
radiation data obtained from the National Center for Environmental Prediction (NCEP), prepared by Qian et al. [2006]. The time-step of model integration is 30 minutes, and the model is run at $2.5^{\circ} \times 1.875^{\circ}$ spatial resolution.

We performed an additional run with a $64 \%$ lower tropical $\mathrm{V}_{\max 25}$ (maximum carboxylation, $\mathrm{V}_{\max }$, at $25^{\circ} \mathrm{C}$ ) following Kattge et al., (2009), who suggest that $\mathrm{V}_{\max }$ for tropical evergreen forests may be lower than the values used for NCAR CLM [Bonan et al., 2011]. We ran CLM4 with a $\mathrm{V}_{\max 25}$ using Kattge et al. (2009)'s value just for tropical forests.

\section{Incorporation of fluorescence}

We added solar-induced fluorescence (SIF) to the existing structure of the photosynthesis module in CLM4, using the equations described in van der Tol et al. (2014). Fluorescence is parameterized on the basis of an empirical relationship between the relative light saturation of photosynthesis and NPQ in plants. This relationship was derived from measurements in a variety of plant species using pulse-amplified modulated (PAM) fluorescence along with leaf gas exchange measurements (van der Tol et al. 2014). The plants that were used range from cotton, tobacco and maize at different light, $\mathrm{CO}_{2}$, temperature and nitrogen fertilization. In addition, they used dataset from Flexas et al. (2002) to include the response of water stress in formulating the equations. Here we derive equations from van der Tol et al (2014) such that fluorescence may be estimated from gross photosynthesis, which is calculated in the existing photosynthesis module in CLM.

This article is protected by copyright. All rights reserved. 
Photosynthesis (carbon assimilation or GPP), A, can be represented by a light-use efficiency (LUE) parameterization in the following equation:

$$
A=I \cdot f \cdot \phi_{p} \cdot \frac{1}{k}
$$

where $I$ is the incident photosynthetically active photon flux density (PPFD) or photosynthetically active radiation (PAR), $f$ is the fractional absorption of the incoming light $(I \cdot f$ is absorbed photosynthetically active radiation, APAR), $\phi_{P}$ is the photochemical quantum yield-the efficiency of electron transport per photon absorbed by photosystems [Lambers et al., 1998]—and $k$ is the number of electron equivalents required to reduce one molecule of $\mathrm{CO}_{2}$. Light-useefficiency of photosynthesis $\left(\varepsilon_{p}\right)$ is defined as:

$$
\varepsilon_{p}=\frac{\phi_{p}}{k}
$$

As a first approximation the flux of emitted fluorescence, $F$ can be expressed by an equation analogous to the expression for photosynthesis,

$$
F=I \cdot f \cdot \phi_{F}
$$


where $\phi_{F}$, fluorescence yield (number of photons that fluoresce per absorbed photon) is analogous to $\phi_{P}$ in Equation 1.

The energy absorbed by excited chlorophyll must be transferred to one of: photochemistry (photochemical quenching or $P$ ), non-photochemical quenching, i.e., heat (NPQ), or fluorescence $(F)$. We then partitioned non-photochemical quenching as the sum of fractional heat loss in lightadapted conditions $\left(\phi_{N}\right)$ and in dark-adapted conditions $\left(\phi_{D}\right)$. Thus,

$$
\phi_{P}+\phi_{N}+\phi_{D}+\phi_{F}=1
$$

Next we express the fractions in terms of corresponding rate coefficients, $k$ :

$$
\begin{aligned}
& \phi_{P}=k_{P} /\left(k_{P}+k_{N}+k_{D}+k_{F}\right) \\
& \phi_{N}=k_{N} /\left(k_{P}+k_{N}+k_{D}+k_{F}\right) \\
& \phi_{D}=k_{D} /\left(k_{P}+k_{N}+k_{D}+k_{F}\right) \\
& \phi_{F}=k_{F} /\left(k_{P}+k_{N}+k_{D}+k_{F}\right)
\end{aligned}
$$

Genty et al. (1989) demonstrated that the quantum yield of electron transport can be estimated by measuring fluorescence at different light conditions:

This article is protected by copyright. All rights reserved. 


$$
\phi_{P}=\frac{\phi_{F_{m}^{\prime}}-\phi_{F}}{\phi_{F_{m}^{\prime}}}
$$

Here, $F_{m}^{\prime}$ is maximum fluorescence rate for a light-acclimated leaf when it is exposed to saturating irradiance. In this case, $k_{P}=0$. From equation (5) $F_{m}^{\prime}$ can be written as:

$$
\phi_{F_{m}^{\prime}}=\frac{k_{F}}{k_{F}+k_{D}+k_{N}}
$$

Using equations 6 and 7, we can write fluorescence yield as:

$$
\phi_{F}=\frac{k_{F}}{k_{F}+k_{D}+k_{N}} \cdot\left(1-\phi_{p}\right)
$$

Thus, fluorescence can be estimated if the rate constants and photochemical yield are known.

The four rate coefficients can be linearly scaled with only the ratios of the probability coefficients influencing the results because all the values are scaled by the sum of them (Equation 5). Following van der Tol et al. (2014), we use $k_{F}=0.05$ and $k_{D}=\max (0.03 T+0.0773,0.87)$ where $T$ is temperature in ${ }^{\circ} \mathrm{C}$. The main factor that influences $\phi_{F}$ is $k_{N}$. It varies with the balance of excitation and sink strength of quanta, as suggested by Duysens and Sweers (1963). Lee et al. 
(2013) suggest an empirical formula for $k_{N}$ as a function of the degree of light saturation $x\left(=1-\phi_{P} / \phi_{P_{o}}\right)$

$$
k_{N}=(6.2473 \cdot x-0.5944) \cdot x
$$

Most photosynthesis models, including the one in CLM4, permit calculation of electron transport rates.

$$
\phi_{P}=\phi_{P_{o}} \cdot \frac{J_{e}}{J_{o}}
$$

where $J_{e}$ is the actual electron transport rate calculated from the $\mathrm{CO}_{2}$ exchange data (the carboxylase limited rate), and $J_{o}$ is the maximum possible electron transport calculated from the absorbed PPFD and the dark-adapted rate constants. Stress decreases $\phi_{P}$, and $\phi_{P}$ becomes $\sim 0.4$ under high light conditions [Weiss and Berry, 1987].

In CLM, $J_{o}$ is calculated as:

$$
J_{o}=I \cdot f \cdot \alpha
$$

This article is protected by copyright. All rights reserved. 
where $\alpha$ is quantum efficiency at $25^{\circ} \mathrm{C} . J_{e}$ can be calculated using the light-limited reaction formulation (Oleson et al., 2010), but using the actual photosynthesis rate as the following:

$$
J_{e}=\left\{\begin{array}{ll}
A \frac{c_{i}+2 \Gamma_{*}}{c_{i}-\Gamma_{*}} & \text { for } C_{3} \text { plants } \\
A & \text { for } C_{4} \text { plants }
\end{array}\right\}
$$

where $c_{i}$ is the $\mathrm{CO}_{2}$ concentration within the intercellular air space and $\Gamma_{*}$ is the $\mathrm{CO}_{2}$ concentration at the compensation point. $\phi_{P}$ is calculated using Equation 10, and fluorescence yield $\phi_{F}$ can be calculated using Equation 8 .

Next, SIF $(F)$ is calculated by multiplying $\phi_{F}$ and APAR (Equation 3). APAR in CLM is calculated using a two-stream radiative transfer function. $F$ is the total fluorescence emitted from leaves, and the unit for $F$ here is $\left(\mu \mathrm{mol} / \mathrm{m}^{2} / \mathrm{s}\right)$.

A spectrometer measures fluorescence as a power per solid angle, unit area, and wavelength range $\left(\mathrm{W} / \mathrm{m}^{2} / \mathrm{sr} / \mu \mathrm{m}\right)$. To compare CLM SIF with the measurements from GOSAT, we would have to run a full canopy radiative transfer model just as SCOPE does. However, running a full 60layer canopy radiative transfer model is computationally too expensive. Thus we use the SCOPE

This article is protected by copyright. All rights reserved. 
model and calculate the conversion factor, and apply the factor to the CLM results. SIF at $755 \mathrm{~nm}$ can be converted to $F$ using the following equation:

$$
F_{755 n m}=\frac{F}{\kappa}
$$

Here, $\kappa$ accounts for the integration over all wavelengths in the fluorescence emission spectrum, observing angle and conversion from $\mu \mathrm{mol} / \mathrm{m}^{2} / \mathrm{s}$ to $\mathrm{W} / \mathrm{m}^{2}$.

To calculate $\kappa$, we ran the full SCOPE model including canopy radiative transfer and obtained $F_{755 \mathrm{~nm}}$ and APAR. Then we ran only the biochemistry module of SCOPE using APAR, calculated $\phi_{F}$, and obtained $F$ using Equation (3). We ran the model with varying leaf area index (LAI), leaf angle, and $\mathrm{V}_{\max 25}$. LAI or leaf angle did not influence the $\kappa$ values much $(<5 \%)$. The variable that influences $K$ most is $\mathrm{V}_{\max 25}$ (Figure 1). Chlorophyll concentration also influences $\kappa$, but as chlorophyll concentration is not a part of CLM4 parameterization, we use global average of $40 \mu \mathrm{g} / \mathrm{cm}^{2}$ (Féret et al., 2011). We calculated $\kappa$ from SCOPE and divided $F$ from CLM4 with $\kappa$. Canopy radiative transfer for the SCOPE model was formulated for crops, and thus could be a source for mismatch compared with observations.

This article is protected by copyright. All rights reserved. 


\section{Data}

Flux tower and ground based SIF measurements

For validation purposes, we compared our model results with three diurnal courses of in-situ measured canopy GPP, SIF and other environmental factors. Our data were acquired from the European Space Agency (ESA) funded CEFLES-2 campaign in September 2007 [Rascher et al., 2009], near the village of Marmande, Southern France $\left(44.45^{\circ} \mathrm{N}, 0.18^{\circ} \mathrm{E}\right)$. A FieldSpec Pro III high resolution spectroradiometer (Analytical Spectral Devices, Boulder, USA) (ASD 2002) was installed in the peak footprint of the eddy-covariance tower $30 \mathrm{~m}$ away. Canopy SIF was retrieved from these radiometric data using the 3FLD method (Maier et al. 2003), a modification of the Fraunhofer Line Discrimination (FLD) method introduced by Plascyk (1975). Details on the processing of the flux-tower data to yield GPP and SIF are described in Damm et al. (2010) and Rascher et al. (2009).

\section{Satellite based SIF measurements}

We used satellite-based SIF measurements, obtained from high-resolution spectra covering Fraunhofer lines (narrow absorption features in the solar spectrum) in the 755-772 $\mathrm{nm}$ range. Spectra were recorded by the TANSO Fourier Transform Spectrometer (FTS) onboard the GOSAT, launched on 23 January 2009. The retrieval method as well as data characterization and post-processing are described in detail in Frankenberg et al., (2010 and 2011). Each GOSAT retrieval samples a footprint area $\sim 10 \mathrm{~km}$ in diameter. Averaging in time and space is needed, owing to single measurement statistical noise. Clear-sky condition for the GOSAT data is defined where the retrieved column oxygen concentration from oxygen A-band is 0.9 times of the expected oxygen concentration.

This article is protected by copyright. All rights reserved. 
We used global monthly $2^{\circ} \times 2^{\circ}$ GOSAT SIF retrievals.

\section{Analysis}

GOSAT has a sun-synchronous orbit and samples around 1 $\pm 0.5 \mathrm{PM}$ local time. We used the data only under clear-sky conditions. From the model results, we defined midday values as average values between 12 PM to 2 PM and clear sky as when incoming solar energy is greater than 0.9 times the maximum solar energy for the month.

\section{Results}

\section{The relationship between SIF and GPP}

We incorporated the equations in section 2.3 into SCOPE and studied the response of simulated fluorescence and photosynthesis. Here, we only used the biochemistry part of SCOPE, which was implemented in CLM. For non-stressed leaves at low light level, $\phi_{P}$ is fairly constant at $\sim 0.8$ [Bjorkman and Demmig, 1987], and decreases with increasing light intensity and stress level (Figure 2). At very low light, most of energy is used in photosynthesis, thus $\phi_{\mathrm{W}}$ and $\phi_{F}$ values are small. As the light intensity or stress increases, $\phi_{P}$ increase becomes dominant and both $\phi_{F}$ and $\phi_{F}$ decrease.

Because GPP and SIF are both directly linked with PPFD, we expect GPP and SIF to have a positive relationship (Equations 1 and 3). We can then rearrange Equations 1 and 3 and obtain the following equation:

This article is protected by copyright. All rights reserved. 


$$
A=\frac{\phi_{P}}{\phi_{F}} \cdot \frac{1}{k} F
$$

When $\phi_{P}$ is lower than 0.6 (Figure 3), $\phi_{P}$ is linearly related to $\phi_{F}$. This relationship occurs at APAR $=550 \mu$ molm $^{-2} \mathrm{~s}^{-1}$ for $\mathrm{V}_{\max }=80 \mu$ molm $^{-2} \mathrm{~s}^{-1}$, and at lower incident radiation for lower $\mathrm{V}_{\max }$ (Figure 2). The relationship between $\phi_{B}$ and $\phi_{F}$ can be approximated in the following equation (Figure 3):

$$
\phi_{F}=0.016 \cdot \phi_{P}+0.0068
$$

The linear relationship arises because the increase of nonphotochemical quenching (NPQ) is accompanied by a decrease of both photochemistry and fluorescence [Flexas et al., 2002; Daumard et al., 2010; Galmés et al., 2007] as plants experience stress [e.g. due to lack of water or excessive light; Flexas et al., 2002]. Because $\phi_{F}$ is linearly increasing with $\phi_{F}$ under most conditions (at least when photosynthesis occurs), GPP and SIF should have a positive relationship. However, the relationship is not perfectly linear. Under high stress conditions, the increase of GPP is not as fast as the increase of SIF, and under low light conditions, the increase in SIF is not as fast as GPP. From this reasoning, we expect that the estimated GPP from assuming a linear relationship between GPP and SIF [e.g. Frankenberg et al, 2011b] will have higher values over stressed regions (e.g. savanna) than the actual GPP.

This article is protected by copyright. All rights reserved. 


\section{GPP and SIF from CLM4 simulations}

By comparing modeled fluorescence by CLM4 with available observations, we are able to demonstrate the capability of our model and to suggest improvements of the CLM4 GPP formulation. First, we compare our model results over a diurnal cycle with in-situ measurements of APAR, GPP, and fluorescence from a flux tower (Figure 4). The model captures the diurnal cycle of all variables reasonably well.

Our global model results (5a and b) compare generally well with GOSAT measurements (Figure 5c). The model captures the spatial variability in GOSAT SIF, but the values are too high over tropics (Figures 5a and c). Following Kattge et al. (2009), we performed another run with a lowered $\mathrm{V}_{\max 25}$ value (from 70 to 45 ) just for tropical forests. That adjustment made the simulated SIF values in tropical forest $(5 b)$ become much more similar to the GOSAT SIF values (Figure $5 c)$.

As expected from Equations 1 and 3, SIF and GPP have a positive relationship (Figure 6a and b). The slope calculated from modeled values is equivalent to that derived from GOSAT values (Figure 6). The relationship is mostly driven by the tropical forests, which have the highest productivity, and the regions with close-to-0 productivity. Just as modeled SIF values are higher than GOSAT SIF values, modeled GPP values are higher than GPP estimates from Max-PlanckInstitute for Biogeochemistry (MPI-BGC; Beer et al., 2010). When $\mathrm{V}_{\max }$ values over the tropics are lowered using the value from Kattge et al. (2009), GPP values becomes similar to the MPIBGC values. Although we cannot rule out other causes for this discrepancy, which include the uncertainties in fluorescence parameterization, the negligence of explicit canopy radiative transfer

This article is protected by copyright. All rights reserved. 
in CLM4, and using a single conversion factor from total fluorescence to $755 \mathrm{~nm}$ fluorescence, we suggest that $\mathrm{V}_{\max }$ may be too high in tropical forests.

\section{Discussion}

A common misconception is that fluorescence is the main mechanism for removing excess energy from the reaction center. In fact, fluorescence is an unavoidable, but small, leakage of energy during the light harvesting process in chlorophyll, with maximum fluorescence less than 5\% of absorbed photons even with artificially extreme light intensity [van der Tol et al., 2014]. The main sink for the excess energy is NPQ, a process regulated by metabolic feedback mechanisms to minimize photoinhibition when the absorbed quantum flux is in excess of that needed by carbon reduction and other sinks.

We have shown here that measured SIF values will be useful in constraining the photosynthesis equations in climate models. Parameterization of photosynthesis, such as using a reasonable $\mathrm{V}_{\max }$ value, is critical because it influences stomatal conductance, and eventually energy, water and carbon fluxes. We note that $\mathrm{V}_{\max }$ values also vary as a result of inadequate simulations of stress, but the whole validation is beyond the scope of this paper. We also note that the scaling from leaf-based measurements to GCM grid-scale include many uncertainties, including but not limited to the canopy radiative transfer and heterogeneity of the landscape. Our approach will be useful placeholder for successful scaling from leaf to ecosystem calculating GPP in land surface models. Validating stress factors and studying their influence for the atmospheric processes will be our next step.

This article is protected by copyright. All rights reserved. 


\section{Acknowledgement}

JEL thanks T. Webb, Ari Kornfeld, Eugene Robinson, Andres Change and anonymous reviewers for helpful comments on the earlier version of the paper. The authors thank R. Hutjes for making the flux-tower data available. The authors also benefitted from discussion during a workshop arranged by the W.M. Keck Institute for Space Studies. This work was supported by DOE GOAmazon Program (DE-FG02-14ER65585). The model simulations were performed on Yellowstone, and JEL thanks G. Bonan for the support.

\section{References:}

Amoros-Lopez J, Gomez-Chova L, Vila-Frances J et al. (2008) Evaluation of remote sensing of vegetation fluorescence by the analysis of diurnal cycles. International Journal of Remote Sensing, 29, 5423-5436.

Asner GP, Alencar A (2010) Drought impacts on the Amazon forest: the remote sensing perspective. New Phytologist. 187, 569-578.

Björkman O, Demmig B (1987) Photon yield of $\mathrm{O}_{2}$ evolution and chlorophyll fluorescence characteristics at $77 \mathrm{~K}$ among vascular plants of diverse origins. Planta, 170, 489-504.

Bonan GB, Lawrence PJ, Oleson KW et al. (2011) Improving canopy processes in the Community Land Model version 4 (CLM4) using global flux fields empirically inferred from FLUXNET data. Journal of Geophysical Research, 116, G02014, doi:10.1029/2010JG001593.

Beer, C., et al. (2010) Terrestrial gross carbon dioxide uptake: Global distribution and covariation with climate, Science, 329, 834-838.

This article is protected by copyright. All rights reserved. 
Collatz GJ, Ball JT, Grivet C, Berry JA (1991) Physiological and environmental regulation of stomatal conductance, photosynthesis, and transpiration: a model that includes a laminar boundary layer. Agricultural and Forest Meteorology, 54, 107-136.

Collatz GJ, Ribas-Carbo M, Berry JA (1992) Coupled photosynthesis-stomatal conductance model for leaves of C4 plants. Australian Journal of Plant Physiology, 19, 519-538.

Cox PM, Betts RA, Jones CD et al. (2000) Acceleration of global warming due to carbon-cycle feedbacks in a coupled climate model. Nature, 408, 184-187.

Damm A, Elbers J, Erler A et al. (2010) Remote sensing of sun-induced fluorescence to improve modeling of diurnal courses of gross primary production (GPP), Global Change Biology, 16, 171-186.

Daumard F, Champagne S, Fournier A et al. (2010) A field platform for continuous measurement of canopy fluorescence, IEEE Transactions on Geoscience and Remote Sensing, 48, 3358-3368. Duysens, LNM, Sweers HE (1963) Mechanism of two photochemical reactions in algae as studied by means of fluorescence. Microalgae and Photosynthetic Bacteria (Japanese Society of Plant Physiologists, eds.), 353 372, University of Tokyo Press, Tokyo.

Flexas J, Escalona J, Evain S et al. (2002) Steady state chlorophyll fluorescence (Fs) measurements as a tool to follow variations of net $\mathrm{CO}_{2}$ assimilation and stomatal conductance during water stress in C3 plants. Physiologia Plantarum, 114, 231-240.

Féret J-B, François C, Gitelson A et al. (2011) Optimizing spectral indices and chemometric analysis of leaf chemical properties using radiative transfer modeling. Remote Sensing of Environment, 115.

Frankenberg C, Butz A, and Toon GC (2011) Disentangling chlorophyll fluorescence from atmospheric scattering effects in $\mathrm{O} 2$ A band spectra of reflected sun light, Geophysical Research 
Letters, 38, L03801, doi:10.1029/ 2010GL045896.

Frankenberg C, Fisher JB, Worden J et al. (2011) New global observations of the terrestrial carbon cycle from GOSAT: Patterns of plant fluorescence with gross primary productivity. Geophysical Research Letters 38, L17706.

Friedlingstein, P, Cox P, Betts R et al. (2006) Climate carbon cycle feedback analysis: Results from the C4MIP model intercomparison, Journal of Climate, 19, 3337-3353.

Galmés J. Medrano H. \& Flexas, J. 2007 Photosynthetic limitations in response to water stress and recovery in Mediterranean plants with different growth forms. New Phytologist. 175, 81-93.

Genty B, Briantais JM, Baker NR (1989), The relationship between the quantum yield of photosynthetic electron transport and quenching of chlorophyll fluorescence. Biochimica Et Biophysica Acta, 990, 87-92.

Guanter L, Zhang Y, Jung M et al. (2014) Global and time-resolved monitoring of crop photosynthesis with chlorophyll fluorescence.Proceedings of the National Academy of Sciences of the United States of America, 111, E1327-33.

Huntingford C, Zelazowski P and Galbraith D et al. (2013) Simulated resilience of tropical rainforests to $\mathrm{CO}_{2}$-induced climate change. Nature Geoscience, 6, 268-273, doi:10.1038/ngeo1741.

Joiner JY, Yoshida A, Vasilkov P et al. (2011) First observations of global and seasonal terrestrial chlorophyll fluorescence from space. Biogeosciences, 8, 637-651, doi:10.5194/bg-8637-2011.

This article is protected by copyright. All rights reserved. 
Kattge J, Knorr W, Raddatz T, Wirth C (2009) Quantifying photo- synthetic capacity and its relationship to leaf nitrogen content for global scale terrestrial biosphere models, Global Change Biology, 15, 976-991, doi:10.1111/j.1365-2486.2008.01744.x.

Koster RD, and the GLACE Team (2004) Regions of strong coupling between soil moisture and precipitation. Science, 305, 1138-1140.

Lambers, H, Chapin FS, and Pons TL (1998) Plant physiological ecology. Springer.

Lawrence DM et al. (2011) Parameterization improvements and functional and structural advances in version 4 of the Community Land Model. J. Adv. Model. Earth Syst., 3, M03001, doi:10.1029/2011MS000045.

Lee, J-E., and CK. Boyce (2010), The impact of hydraulic capacity on water and carbon cycles in tropical South America, J. Geophys. Res., 115, D23123, doi:10.1029/2010JD014568.

Lee J-E, Frankenberg C, van der Tol C et al. (2013) Forest productivity and water stress in Amazonia: observations from GOSAT chlorophyll fluorescence. Proceedings of the Royal Society B: Biological Sciences, 280, 1761.

Lee J-E, Lintner B, Neelin J et al. (2012) Reduction of tropical land region precipitation variability via transpiration.Geophysical Research Letters, 39, L19704, doi:10.1029/2012GL053417.

Lichtenthaler HK, Rinderle U (1988) The role of chlorophyll fluorescence in the detection of stress conditions in plants. Critical Reviews in Analytical Chemistry, 19, S29-S85.

Meroni M, Rissubu N, Guanter L et al. (2009) Remote sensing of solar-induced chlorophyll fluorescence: Review of methods and applications. Remote Sensing of Environment, 113, 20372051.

This article is protected by copyright. All rights reserved. 
Oleson, KW, Lawrence, DM, Gordon, B et al. (2010). Technical description of version 4.0 of the Community Land Model (CLM). NCAR/TN-478+STR.

Qian T, Dai A, Trenberth KE, Oleson KW (2006) Simulation of global land surface conditions from 1948 to 2004. Part I: Forcing data and evaluations. Journal of Hydrometeorology, 7, 953975.

Rascher U, Agati G, Alonso L et al. (2009) CEFLES 2: The remote sensing component to quantify photosynthetic efficiency from the leaf to the region by measuring sun-induced fluorescence in the oxygen absorption bands, Biogeosciences, 6, 1181-1198.

Saleska SR, Miller SD, Matross DM et al. (2007) Amazon Forests Green-Up During 2005 Drought. Science, 318, 612, doi:10.1126/science.1146663.

Samanta A, Sangram G, Hashimoto H et al. (2010) Amazon forests did not green-up during 2005 drought. Geophysical Research Letters, 37, 1-5.

Solomon S et al. (2007) Climate Change 2007: The Physical Science Basis. Contribution of Working Group I to the Fourth Assessment Report of the Intergovernmental Panel on Climate Change [Solomon, S., D. Qin, M. Manning, Z. Chen, M. Marquis, K.B. Averyt, M. Tignor and H.L. Miller (eds.)]. Cambridge University Press, Cambridge, United Kingdom and New York, NY, USA.

Van der Tol C, Verhoef W, Rosema A (2009a) A model for chlorophyll fluorescence and photosynthesis at leaf scale. Agricultural and Forest Meteorology, 149, 96-105

Van der Tol C, Verhoef W, Timmermans J et al. (2009b) An integrated model of soil - canopy spectral radiances, photosynthesis, fluorescence, temperature and energy balance. Biogeosciences 6,3109 .

Verhoef W (1984) Light scattering by leaf layers with application to canopy reflectance modeling: The SAIL model. Remote Sensing of Environment, 16, 125-141.

This article is protected by copyright. All rights reserved. 
Verhoef W (2005). Extension of SAIL to model solar-induced canopy fluorescence spectra. Proceedings of the 2nd Workshop on Remote Sensing of Vegetation Fluorescence, Montreal, Canada, 17-19 November 2004.

Weis E, Berry, JA (1987) Quantum efficiency of Photosystem II in relation to 'energy'-dependent quenching of chlorophyll fluorescence. Biochimica Et Biophysica Acta, 894, 198-208.

\section{Figure captions:}

Figure 1. The conversion factor $\kappa$ from leaf-level fluorescence $\left(\mu \mathrm{molm} \mathrm{m}^{-2} \mathrm{~s}^{-1}\right)$ to spectrometerobserved fluorescence at $755 \mathrm{~nm}\left(\mathrm{Wm}^{-2} \mathrm{sr}^{-1} \mu \mathrm{m}^{-1}\right)$ in Equation 13 at different $\mathrm{V}_{\max 25}$. Chlorophyll concentration of $40 \mu \mathrm{gcm}^{-2}$ is used. $\kappa$ accounts for the integration for the whole fluorescence spectrum, observing angle and conversion from $\mu \mathrm{mol} / \mathrm{m}^{2} / \mathrm{s}$ to $\mathrm{W} / \mathrm{m}^{2}$. CLM uses $\mathrm{V}_{\max 25}$ from 40 to 70.

Figure 2. The fraction of light (yield) that is used for photochemistry $\left(\phi_{P}\right)$, fluorescence $\left(\phi_{F}\right)$ and non-photochemical quenching (NPQ; $\phi_{D}+\phi_{N}$ ) (left column) and actual rates (yield multiplied by APAR; $\mu$ molm $^{-2} \mathrm{~s}^{-1}$; right column) with increasing APAR. The values are from SCOPE model simulations. Three lines represent different $\mathrm{V}_{\max }$ values $\left(40,60,80 \mu \mathrm{molm}^{-2} \mathrm{~s}^{-1}\right)$.

Figure 3. The relationship between photochemical yield $\left(\phi_{P}\right)$ and SIF yield $\left(\phi_{F}\right)$ (top panel) and the response of photochemical yield (blue) and SIF yield (red) as non-photochemical quenching (NPQ; $\phi_{D}+\phi_{N}$ ) varies. The values are calculated from SCOPE, varying $\mathrm{V}_{\max }$ and light intensity. Note that the photochemical yield decreases almost linearly with increasing NPQ yield and that SIF yield is much smaller compared with other terms. This relation was derived from leaf-level 
measurements [van der Tol et al., 2014] and the applicability of the whole canopy is not yet certain.

Figure 4. Diurnal variations in APAR, assimilation ( $A$ or GPP), and SIF over the flux tower site in Marmande, Southern France $\left(44.45^{\circ} \mathrm{N}, 0.18^{\circ} \mathrm{E}\right)$. Blue line represents the CLM4 result and red dots represent measured values over the flux tower.

Figure 5. Global map of annual mean SIF $\left(\mu \mathrm{Wm}^{-2} \mu \mathrm{m}^{-1}\right)$ from (a) CLM control (b) CLM with lower tropical $\mathrm{V}_{\max }$ and (c) GOSAT. We used global $2^{\circ} \times 2^{\circ}$ GOSAT SIF retrievals and $2.5^{\circ} \times 1.875^{\circ} \mathrm{CLM}$ simulations.

Figure 6. The relationship between annual mean SIF and GPP: (a) GOSAT SIF and MPI-BGC GPP, (b) CLM SIF and CLM GPP from the control case, and (c) CLM SIF and CLM GPP from the case with lower tropical $\mathrm{V}_{\max }$. We used global $2^{\circ} \times 2^{\circ}$ GOSAT SIF retrievals and $2.5^{\circ} \times 1.875^{\circ}$ CLM simulations. The points in the plot cover annual mean and all vegetated land surface.

This article is protected by copyright. All rights reserved. 


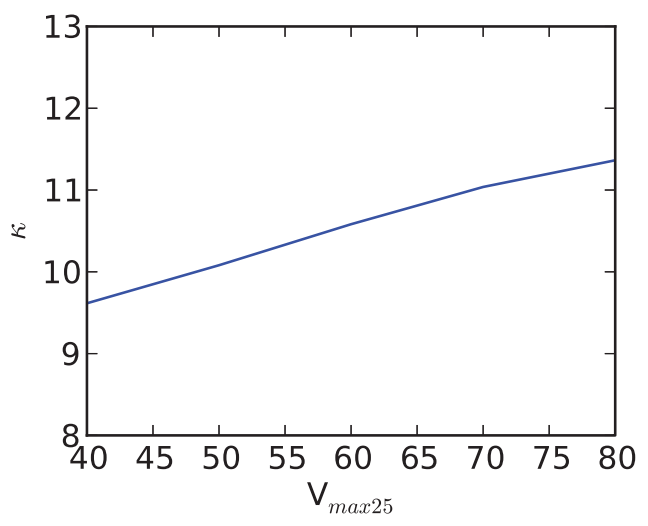

This article is protected by copyright. All rights reserved. 

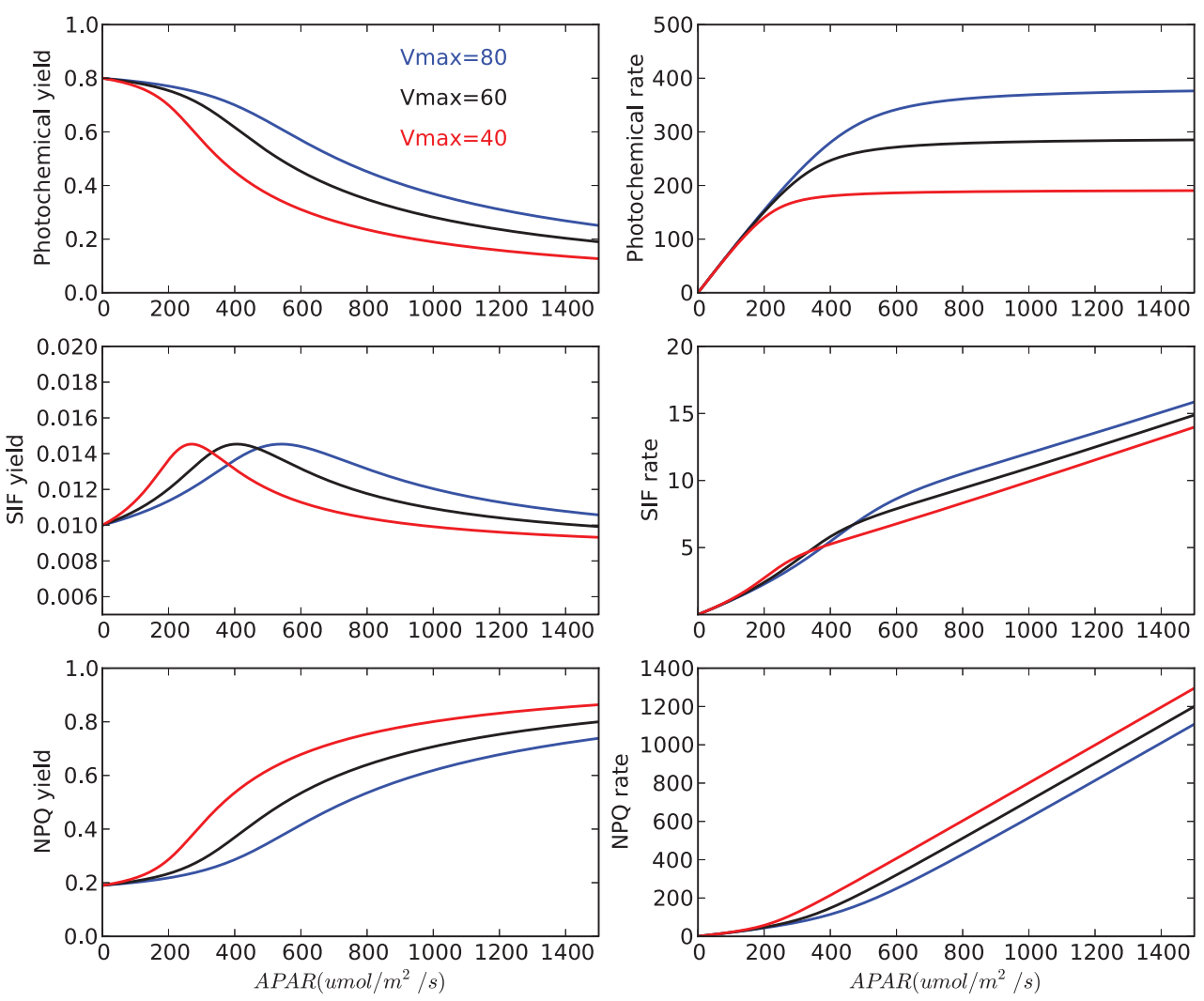

This article is protected by copyright. All rights reserved. 

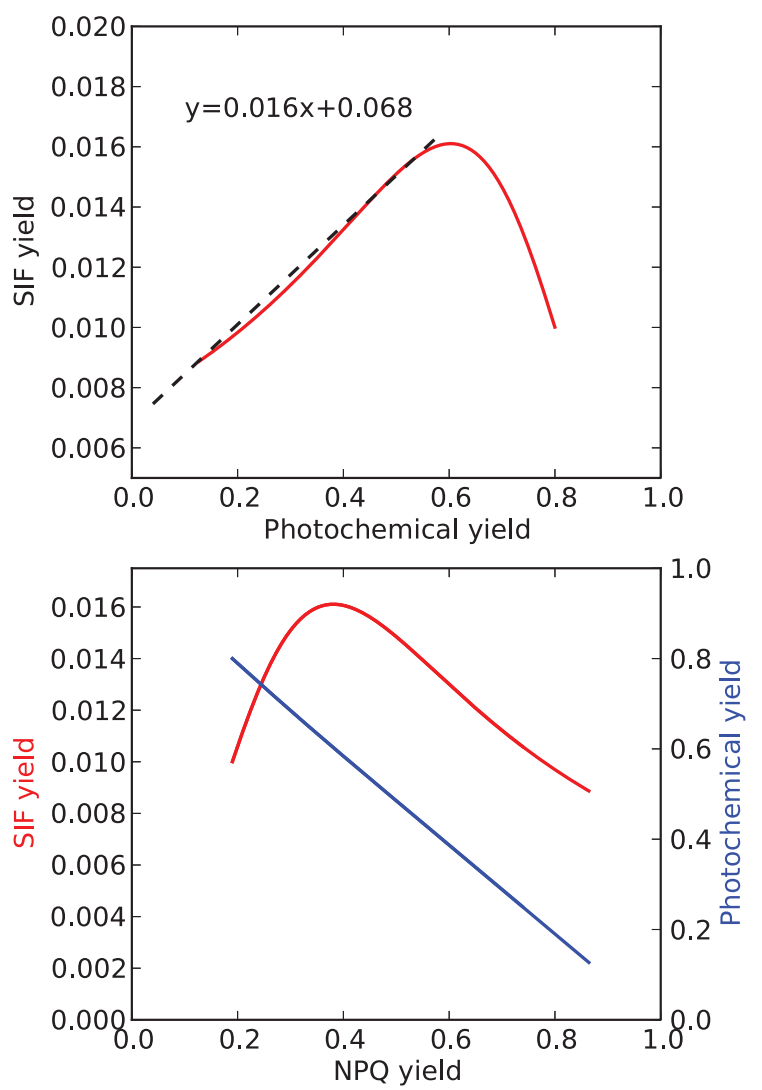

This article is protected by copyright. All rights reserved. 

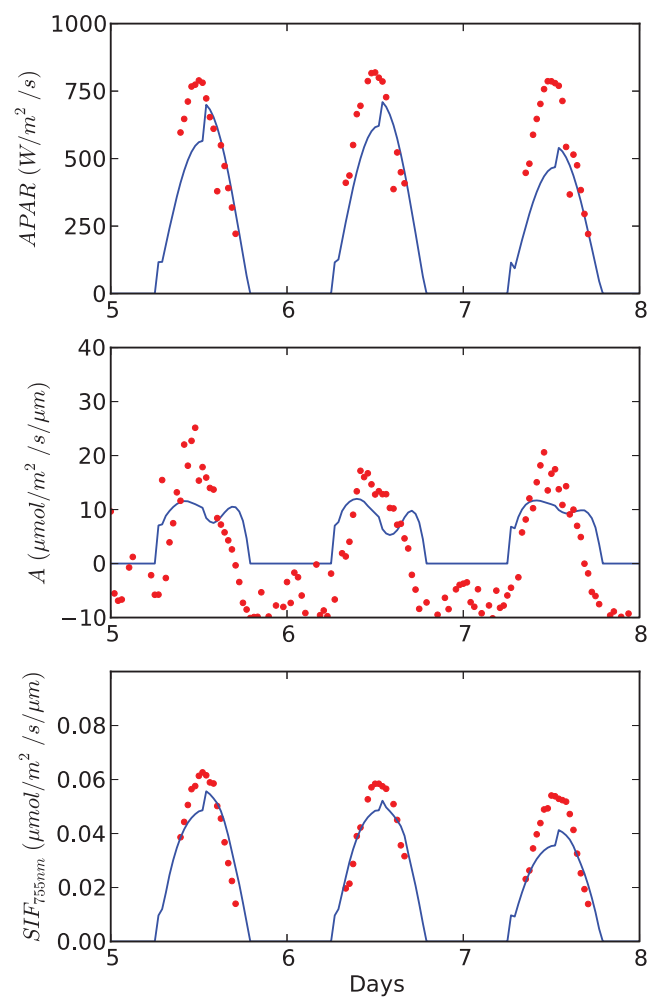

This article is protected by copyright. All rights reserved. 

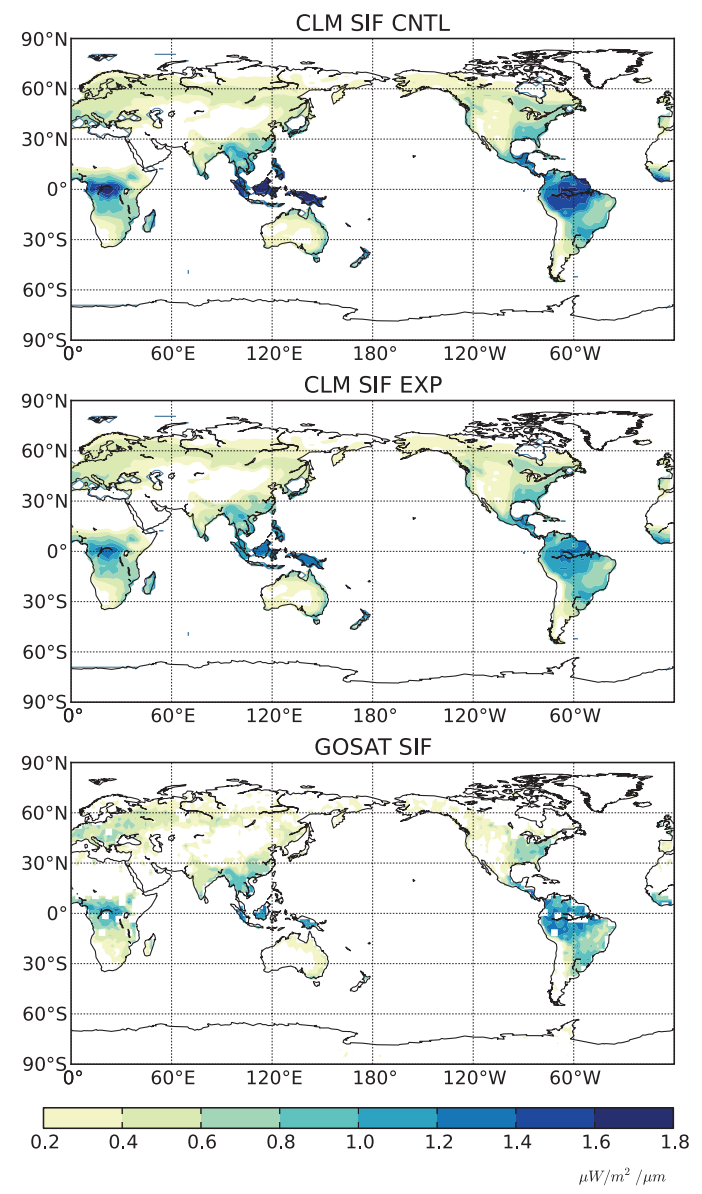

This article is protected by copyright. All rights reserved. 

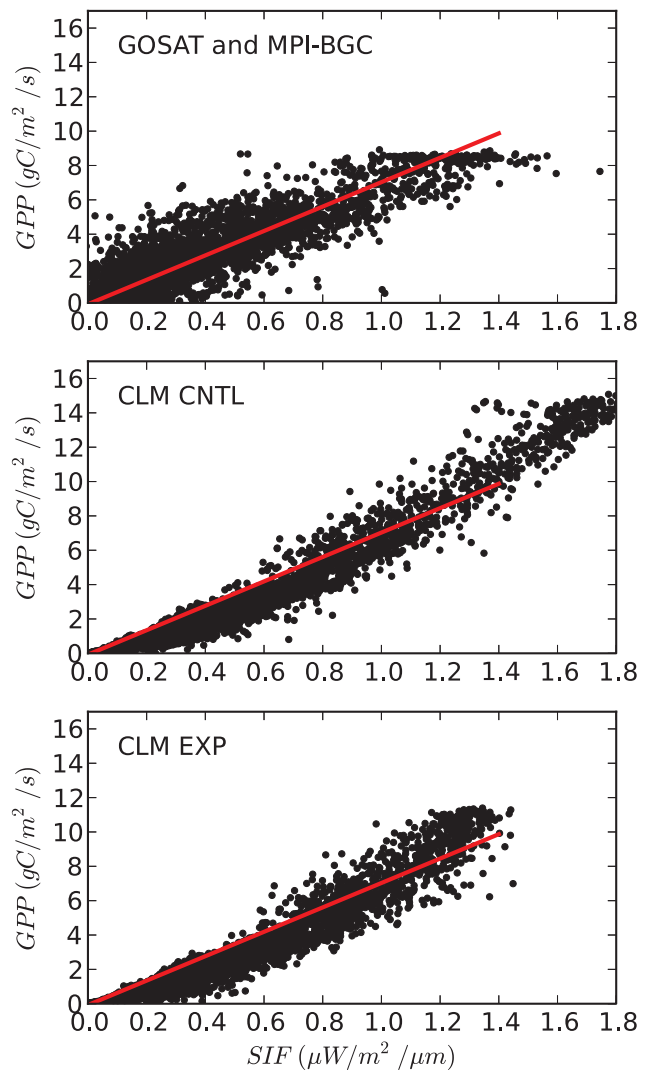

This article is protected by copyright. All rights reserved. 